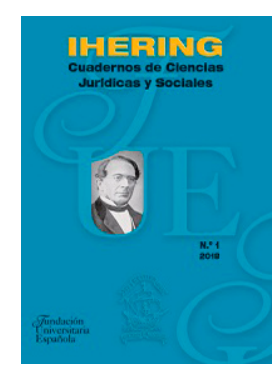

\author{
Ihering. Cuadernos de Ciencias Jurídicas y Sociales \\ $\mathrm{N}^{\mathrm{o}} 2$
}

Año: 2019

e-issn: 2660-552X

DOI: https://doi.org/10.51743/ihering.22

(a) $(1) \Theta$

\title{
El Derecho como organización \\ de fuerzas históricas: Alfred Döblin, Woodrow \\ Wilson, Sófocles, y Noviembre de 1918
}

\author{
ENRIQUe SAN Miguel PÉREZ \\ Catedrático de Historia del Derecho y de las Instituciones \\ Universidad Rey Juan Carlos. Madrid \\ Profesor Visitante \\ Universidad Miguel de Cervantes. Santiago de Chile
}

\section{Resumen}

La República de Weimar encierra la histórica creación de una nueva solución política con instituciones democráticas y el pleno desarrollo de los derechos humanos y sociales. Berlín se convirtió, junto con Viena, en el centro mundial de la creación artística y cultural. Noviembre de 1918, de Alfred Döblin, muestra una brillante visión de la edificación de la República tras la quiebra de la Alemania imperial, y de un Estado de Derecho que hace frete al autoritarismo.

\section{Palabras clave}

Estado de Derecho. Democracia. Derechos sociales. Creación cultural.

\begin{abstract}
Weimar Germany represents the historical creation of a new political solution with democratic institutions, and full development of human and social rights. Moreover, Berlin became, alongside with Vienna, the world centre of arts and cultural creativity. Alfred Döblin's November 1918 shows a brilliant vision of the rose of the Re-
\end{abstract}


public after the collapse of imperial Germany, and the rule of law, facing the growing authoritarianism.

\section{Key words}

Rule of Law. Democracy. Social rights. Cultural creativity.

66 ún hoy temo despertarme una mañana con un billete de un millón Ade marcos en la mano". Fred Uhlman, inmenso escritor y gran artista plástico, militante y activista del SPD que hubo de abandonar su país cuando el acceso del nazismo al poder se hizo inevitable y, por lo tanto, ferviente partidario del régimen republicano alemán, evocaba medio siglo después su juventud alemana. Y, por muchos conceptos, resumía el contenido profundo que, incluso para los demócratas más dispuestos a sacrificarse en el combate contra el totalitarismo, representaba el recuerdo de la Alemania de Weimar ${ }^{1}$.

Cuando en 1922, el "año del Doctor Mabuse", estalló la hiperinflación que habría de signar la historia de la república de Weimar y, por muchos conceptos, la historia alemana desde entonces ${ }^{2}$, y quienes habían ahorrado se arruinaron mientras los endeudados mejoraban sus posibilidades e, incluso, los más audaces se enriquecían aplicando una lógica especulativa contraria al clásico itinerario de prosperidad que se fundamentaba en el trabajo, la honestidad, la responsabilidad y el orden. Una nueva generación, la de los jóvenes de posguerra, asistió atónita al desmoronamiento de todos los principios en los que se habían formado sus mayores. La ausencia de escrúpulos y el sentimiento de que un mundo hostil únicamente podía regirse por la dominación y la violencia impunes habría de denotar a quienes habrían de convertirse en perpetradores de terribles crímenes.

${ }^{1}$ UHLMAN, F.: Brilla el sol en París. Madrid. 1987, p. 94.

${ }^{2}$ FELDMAN, G. D.: The Great Disorder. Politics, Economics, and Society in the German Inflation 1914-1924. Oxford. 1997, pp. 513 y ss. 
La sensación apocalíptica, incluso la tentación casi soberbia de enfrentamiento con el final de los tiempos, igualmente, se apoderó de pensadores y creadores. La Alemania imperial había desarrollado un también sólido sistema universitario y un clima de creación e investigación que habría de desembocar en un hecho tan asombroso como que entre 1918 y 1933 obtuviera 16 Premios Nobel, comenzando en 1918 por el obtenido por Max Planck. Un Estado militarizado era, al mismo tiempo, el centro académico más potente del mundo en todas las grandes disciplinas científico-técnicas ${ }^{3}$.

Pero el portentoso despliegue académico, universitario y cultural de Alemania no habría de acertar a consolidar una institucionalidad democrática que, tras la aprobación de la Constitución de Weimar de 1919, surgía con aportaciones conceptuales de enorme relieve en el ámbito de la ampliación de los derechos sociales y la profundización de la lectura democrática del nuevo orden republicano. Cuando se leen extraordinarios trabajos, como el de Dirk Blasius, sobre la crisis de la República alemana, y su destrucción, se cierne sobre el lector, una vez más, una sensación fatídica: el sistema de Weimar parecía estar condenado, y desde un principio, a un pronto, abrupto y dramático final, en medio de un contexto casi bélico ${ }^{4}$. Pero, como Manuel García Pelayo habría de poner de manifiesto, la instauración de la República parlamentaria de 1919 comportó la creación de un modelo político e institucional denotado por su sensibilidad social, y el compromiso con la efectiva tutela judicial de un más amplio elenco de derechos y libertades fundamentales, es decir, el desarrollo de los poderes públicos al servicio de una ciudadanía más allá de la "procura existencial", dentro de una más integral concepción de la acción política y de gobierno ${ }^{5}$.

Alfred Döblin fue uno de los novelistas que mejor ejemplificaron el compromiso, en todo caso muy crítico, con la innovadora solución política salida del colapso de la Alemania prusiana, pero también del fracaso y violenta

\footnotetext{
${ }^{3}$ RABINBACH, A.: In the shadow of catastrophe. German Intellectuals between Apocalypse and Enlightenment. Berkeley and Los Ángeles. 1997, pp. 6 y ss.

${ }^{4}$ BLASIUS, D.: Weimars ende. Bürgerkrieg und Politik 1930-1933. Frankfurt am Main. 2008, pp. 174 y ss.

${ }^{5}$ GARCÍA-PELAYO, M.: Las transformaciones del Estado contemporáneo. Madrid. 1977, pp. 73 y ss.
} 
represión de la revolución espartaquista. Médico psiquiatra proveniente de Pomerania, de origen judío y amigo de Bertolt Brecht, y converso al catolicismo en sus años finales de existencia, Döblin representa muy bien el alma de la Alemania de Weimar, dotada de un fondo profundamente científico y racionalista, pero al mismo tiempo nutrida por una no menos severa inquietud por el destino de la civilización, enraizada en la tradición liberal e idealista de la Alemania romántica.

Berlín Alexanderplatz es, sin duda, su mejor novela. Publicada en un año tan emblemático como 1929, en el que Alemania, además de enfrentarse al estallido de una gigantesca crisis económica, perdió a Gustav Stresemann, uno de los líderes que sostenían el sistema político de Weimar, el autor recrea admirablemente el clima singular de una metrópoli que, por muchos conceptos, y junto a Viena, se había convertido en el centro mundial de los grandes creadores. En una reseña a su propio libro publicada en 1932, el mismo Alfred Döblin describía qué había querido aportar con su monográfica reflexión sobre el albañil Franz Biberkopf y, con él, sobre cuanto contemplaba en el Este de Berlín:

"Aquí veía una clase hombres interesante y, sobre todo auténtica y todavía no descrita. He podido observar a esa clase de hombres en los momentos más diversos y en las situaciones más diversas, y la he observado de la única forma verdadera: viviendo, tratando y sufriendo con ellos. Vi aquí la paz, vi ocasionalmente la guerra, cuando vine de permiso, y estuve luego otra vez entre ellos en el alzamiento espartaquista de 1919, en la inflación y en la época que siguió" ${ }^{6}$.

La angustia de Döblin, médico militar durante la Gran Guerra, provenía de su turbadora experiencia en los campos de batalla y los hospitales de campaña, y la vivencia de la crueldad despiadada y sin límites. El año 1918,

${ }^{6}$ DÖBLIN, A.: Berlín Alexanderplatz. Barcelona. 1982, p. 462: “...este mundo es un mundo de dos dioses. Es un mundo de construcción y destrucción simultáneas. Ese enfrentamiento se produce en la temporalidad, y nosotros participamos en él. Y este razonamiento filosófico enlaza con el anterior sobre la delincuencia. La sociedad está socavada por la delincuencia, dije. ¿Qué quiere decir eso? Hay en ella orden y descomposición. Pero no es cierto que el orden, que sólo la forma y la existencia sean reales, sin la tendencia a la descomposición y a la destrucción fáctica". 
precisamente, apareció Wadzek contra la turbina de vapor, recientemente traducida al castellano, en donde el desarrollo industrial y la competencia exacerbada se resuelve en el retorno al origen o la emigración, pero en donde el fabricante nunca se da por vencido, es decir, en un intento de explicación de la lógica del capitalismo y del imperialismo a ultranza que había conducido a la, hasta entonces, más amplia conflagración bélica de la historia ${ }^{7}$.

Para Alemania, la derrota en 1918 era inexplicable para buena parte de una ciudadanía que, muy distante de los frentes, no había padecido en toda su extensión los horrores de la guerra. Y, por tanto, únicamente la traición podía otorgar sentido a la victoria aliada. Pero, además, la derrota se convirtió en una experiencia cotidiana, visible tras el regreso de los soldados. Eric Weitz ha destacado hasta qué punto los veteranos que volvieron a Alemania se convirtieron en personas molestas, especialmente cuando se encontraban severamente heridas y erosionaban la mala conciencia de sus compatriotas. Veteranos que, además, evocaban la memoria de tiempos felices y plenos, los anteriores al estallido de la contienda ${ }^{8}$.

Tras la conclusión de la II Guerra Mundial, tras un prolongado exilio que se había iniciado con el acceso al poder de los nazis, y que se había desarrollado esencialmente en los Estados Unidos y en Francia, Döblin decidió dar forma a su experiencia histórica como ciudadano de la Alemania que se quebró tras la finalización de la I Guerra Mundial. El proyecto literario se transformó en una amplia y ambiciosa tetralogía completada en apenas dos años, entre 1949 y 1950, denominada Noviembre de 1918, y comienza con Burgueses y soldados, una obra en donde se describe el repliegue del ejército alemán tras el armisticio impuesto por el mariscal Foch a los negociadores alemanes, el antiguo diputado del Reichstag y secretario de Estado Erzberger y el general von Winterfeldt. Un repliegue que, como la propia escasez que sobreviene tras la conclusión del conflicto, se produce en orden, en un país todavía regido por sus viejos principios y códigos de conducta.:

"Los ejércitos alemanes se retiraban en orden, eran hombres y obedecían, tenían vehículos y piezas de artillería. Que los cañones atronaran no era

\footnotetext{
${ }^{7}$ DÖBLIN, A.: Wadzek contra la turbina de vapor. Salamanca. 2011, p. 401.

${ }^{8}$ WEITZ, E. D.: Weimar Germany. Promise and Tragedy. Princeton. 2007, pp. 10 y 22.
} 
ninguna novedad para ellos. No sentían la necesidad de gritar al ver aviones. En los pequeños pueblos que abandonaban, mataban a los perros y gatos que quedaban para evitarles la muerte por hambre. Se veían rodeados de refugiados hambrientos. Allá donde ponían sus humeantes cocinas de campaña, entre los hombres se abrían paso mujeres y niños. No se entendía el lenguaje de aquellos míseros y temblorosos grupos, pero quien tendía un cuenco, una escudilla, se la llevaba llena. No era ningún banquete, pero se daba lo que se tenía... La gente compartía su pan con los refugiados; se comía y se veía a los niños masticar sus mendrugos; qué terrible destino, pequeños, ¿qué es la guerra?, ¿para qué es?, en casa nosotros también tenemos pequeños como estos, quizás ahora la guerra también nos alcance, hemos perdido. Seguía la retirada. De los vagones de tren, de los avantrenes, se colgaban mujeres y niños mendicantes. A los niños mayores que yacían agotados en los caminos, se los sentaba sobre los cañones y se los llevaba hasta el pueblo siguiente" ${ }^{9}$.

La ordenada retirada del ejército alemán suscita desde el principio la incomodidad de los mandos franceses. El mariscal Foch ha determinado en el armisticio del 11 de noviembre unas condiciones de casi imposible cumplimiento, sin precedentes por su dureza, pero también por el desafío logístico que representa para el ejército derrotado ${ }^{10}$. Sin embargo, el repliegue tras el Rin de tres millones de soldados sin apenas incidentes representa, en la perspectiva de Döblin, el último testimonio de un proyecto de Estado, de organi-

${ }^{9}$ DÖBLIN, A.: Noviembre de 1918. Burgueses y soldados. Barcelona. 2011, pp. 282-283 y 428: “ 'Según la decisión de Foch, han de entrar en vigor condiciones de armisticio tales como nunca han sido impuestas en la historia. Un moderno ejército de tres millones de hombres, con un complicado aparato técnico, ha de ser llevado en perfecto orden al otro lado del Rin a marchas forzadas, en una época del año desfavorable, por caminos malos y montañosos' “.

${ }^{10}$ Ibidem, pp. 432-433: "-Mienten; estos alemanes mienten. Se atreven a negar su derrota en medio de la derrota... Hay que meterles en la cabeza la batalla del Marne, la fracasada ofensiva de primavera de Ludendorff, el fracasado ataque de Amiens...

-... Hacen como si no supieran los estragos que hicieron en Bélgica y el norte de Francia entre la población civil desarmada. Han lanzado a decenas de miles de los suyos a sus ofensivas $\mathrm{y}$ los han sacrificado sin pestañear, $\mathrm{y}$ ahora hacen como si les importase que algunos quedaran en el camino en las marchas forzadas o cayeran presos. ¿Qué pretenden con estas bajezas? Sustraerse a las consecuencias de la derrota... No rehúyen el gimoteo de los esclavos y lo mezclan con todos esos desatinos de paz, reconciliación y justicia que el presidente Wilson se ha traído de la Universidad de Princeton". 
zación civil y, casi de civilización, inspirado por principios seculares vertebrados por el sentido del cumplimiento de las normas.

Es en la siguiente entrega de la tetralogía, El regreso de las tropas del frente, en donde Alfred Döblin somete a un exhaustivo examen a la nueva institucionalidad alemana establecida tras la marcha del emperador Guillermo al exilio en los Países Bajos y la proclamación de una República cuyo gobierno provisional preside el líder del SPD, Friedrich Ebert. Desde el principio, Döblin presenta a Ebert como un convencido continuador de la lógica política imperial, cuyo objetivo esencial reside en la asunción de todo el poder en la nueva República, y eso significa la implantación de un sentido del orden incompatible con el proyecto revolucionario del KPD, y sobre todo de dos figuras que, además de contar con todas las simpatías de Döblin, se convierten en los verdaderos protagonistas de su corpus narrativo: Karl Liebneckt y Rosa Luxemburgo, centro absoluto del último y vibrante que cierra la tetralogía.

El 11 de noviembre precedente, con motivo de la formación del gobierno provisional, el mariscal Hindenburg había puesto a su disposición la lealtad del formidable dispositivo militar del imperio, garantizando la continuidad de las instituciones bajo el liderazgo socialdemócrata siempre que se disolvieran los consejos de soldados que preconizaban la revolución. Por eso, cuando Ebert, ya presidente del gobierno provisional, salió al parque Lustgarten de Berlín, se dirigió a la ciudadanía en términos inequívocos:

“-Nosotros, los del SPD -gritó el hombrecillo regordete y bigotudo, visiblemente indignado representante de la razón humana-, queremos paz, pan y libertad. Queremos democracia. Sin democracia no hay libertad...

-...La violencia siempre es reaccionaria. Todos los días, los fanáticos adeptos de Liebknecht llaman a la violencia. Reparten armas. Amenazan con atacar al Gobierno por la fuerza de las armas. Saldremos al paso de tales intentos con la mayor decisión.

Gritos: 'Mantener la palabra. Sujetar fuerte'.

-No dudamos de que las elecciones a la Asamblea Nacional mostrarán a todo el mundo que los cincuenta años de trabajo educativo de la socialdemocracia alemana se han convertido en un bien común de los trabajadores alemanes. La Constituyente será una victoria del SPD. Vi- 
va la libertad, la democracia, la Asamblea Nacional, la vieja socialdemocracia alemana" ${ }^{11}$.

Ebert y el SPD habrían de convertirse, sobre todas, en garantes del orden constitucional naciente en 1919. Martín Kriele habría de razonar con su habitual agudeza la naturaleza inevitablemente conservadora de una república surgida como alternativa a la derrota en la Gran Guerra, pero también a las revoluciones comunistas continuadoras de la revolución rusa de octubre de $1917^{12}$. Döblin aporta sustento histórico, experiencial y literario a las tesis de Martin Kriele. En su visión de madurez, vecina a su propio fallecimiento, el novelista de Stettin mantiene la continuidad entre la Alemania imperial y la republicana sobre la base del respeto a la legalidad y el cumplimiento de la ley. No hay revolución ni ruptura, sino evolución y reforma.

Alfred Döblin defiende el valor de la ley y de la institucionalidad democrática como fuerzas motrices del proyecto de civilización, comenzando por la propia vocación de paz y de orden de una Alemania que debe contribuir a la consolidación de un sistema republicano y una Europa distantes de toda tentación de revancha y, no digamos, totalitaria. Por eso, y junto a Friedrich Ebert, en su tetralogía ocupa una posición de privilegio una figura que habría de conocer como alemán y estudiar durante su estancia en los Estados Unidos: Woodrow Wilson, jurista y politólogo, presidente de Princeton y después presidente de los Estados Unidos entre 1913 y 1921. Su presentación de la figura que habría de irrumpir en Europa como seguramente la personalidad histórica que más positivas expectativas y simpatías había nunca generado y, por consiguiente, quien habría de abandonar Europa envuelto en un clima de creciente decepción y desafección, multiplicadas en los Estados

${ }^{11}$ DÖBLIN, A.: Noviembre de 1918. El regreso de las tropas del frente. Barcelona. 2013, pp. 81 y 79 : “...me he aliado con usted para salvar a nuestro pueblo del derrumbamiento que lo amenaza...

Según mi convicción, sólo las siguientes medidas pueden salvarnos de las actuales dificultades:

1. La inmediata convocatoria de la Asamblea Nacional.

2. Todos los asuntos deberán ser gestionados exclusivamente por la corporación legislativa.

3. Los Consejos de obreros y soldados representarán únicamente un papel consultivo' “.

${ }^{12}$ KRIELE, M.: Einführung in die Staatslehre. Die geschichtlichen Legitimitätsgrundlagen des demokratischen Verfassungsstaates. Darmstadt. 1994, pp. 333 y ss. 
Unidos, se realiza en la novela con apenas unas breves, pero sumamente reveladoras pinceladas:

“...Europa yacía cansada y desgarrada. Se aproximaba el embajador de la honestidad, de la conciencia, representante del país que no era 'un hecho geográfico, sino un hecho moral'...

Era un hombre solitario, introvertido. Sentía que Dios le había encargado una pesada carga. Estaba decidido a llevarla. En el barco, dijo a sus acompañantes:

'Si ahora no manejamos con cuidado los poderes que la humanidad ha puesto en nuestras manos quedaremos a los ojos de todos como los peores fracasados de la historia universal, por nuestra propia culpa y merecidamente' “ 13 .

Wilson había mantenido en El Estado que la solución estatal era la fórmula que aportaba racionalidad a la vida social, a la convivencia, y al propio proceso de emancipación humana ${ }^{14}$. Pero, de la misma forma que sus conceptos eran rotundos y bienintencionados, manifestaban también un considerable esquematismo dentro de un análisis histórico de la evolución de las formaciones estatales europeas en donde resultaban más que evidente unos enormes prejuicios, seguramente escolares y, en todo caso, no lo bastante razonados, contra los Hohenzollern y, sobre todo, los Habsburgo, que delataban un manifiesto desconocimiento de la propia realidad austriaca y, sobremanera, vienesa, de su tiempo. Alfred Döblin no vacila en mostrar esas insuficiencias de Wilson, dentro de su visión

${ }^{13}$ DÖBLIN, A.: El regreso de las tropas del frente..., pp. 16 y 15: “ 'Sólo hay una respuesta para el desafío de Alemania: la fuerza, la fuerza hasta el final, la fuerza sin restricciones y sin límites. La energía que tiene dignidad triunfará, la energía que, a partir del Derecho, crea la Ley universal y hacer morder el polvo a todos los Gobiernos egoístas.

¿Pueden una potencia militar o un grupo de naciones decidir el destino de los pueblos, sobre los que no tienen otro derecho que la fuerza? ¿Es que las naciones poderosas van a poder someter a las débiles? ¿Deben los pueblos seguir soportando la voluntad de otros, sin poder hacer valer su propia voz? ¿Se hará realidad un ideal común para todos los pueblos, o el poderoso podrá seguir actuando como quiera y atormentar impune a los débiles? ¿Se pueden dejar arbitrariamente a un lado las exigencias del Derecho, o deben tener vigencia los acuerdos que impongan la obligación del Derecho?".

${ }^{14}$ WILSON, W.: The State. Princeton. 1900, pp. 111 y ss. Vid. igualmente MACMILLAN, M.: Peacemakers. The Paris Conference of 1919 and Its Attempt to End War. London. 2003, pp. 62 y ss. 
casi mística de la historia humana, y dedicar algunas de sus mejores y más analíticas páginas, al modo en que el presidente exhibe su visión despótico-profesoral de la condición humana:

"Los alemanes han derribado a sus gobiernos. Ahora tenemos que ayudarles a encontrar la forma de gobierno adecuada, y apoyarles. ¿Qué vendrá ahora? ¿Quién sabe? ¿Cuál es la mayor lucha de la historia universal? La que se libra entre los pueblos y sus gobernantes. Empieza en la Biblia, con Moisés. Entonces el gobernante luchaba por su pueblo. Los judíos estaban en Egipto, eran un pueblo esclavo y eran maltratados por sus amos. Entre ellos, Moisés era realmente un líder, había nacido para eso y les había sido destinado por Dios. Pero tuvo que recurrir a la magia para que le escucharan. En cuanto volvía la espalda, se comportaban como escolares a los que se deja sin vigilancia. Pero su lucha es la excepción. La regla es lo contrario: un pueblo trata de defenderse de sus tiránicos amos. ¡Hay mil ejemplos! Ahora, cuando viajo a Europa como representante de una verdadera democracia, no soy tan ciego como algunos se figuran. Los cínicos del mundo han acordado entre ellos que sólo el cinismo es la razón. No conocen los sentimientos humanos, juegan a pasarse la pelota con ellos. Y dominan la política. Forman una clac. Se oponen a los pueblos. Han sabido colarse para ponerse a la cabeza de los pueblos, también en los Parlamentos. El pueblo es para ellos un negocio...

...ंcuál ha sido la peor guerra de la historia universal, la que hasta ahora nunca ha concluido? La de los pueblos contra sus políticos y gobiernos. Suprema rareza: una democracia sincera. la democracia es sincera cuando tiene una dirección consciente de su responsabilidad... ¿Quién ha instigado esta guerra? Gobiernos autocráticos... ¿Quién puede hacer la paz? ¿Gobiernos como ésos? ¿Cuál podría ser el resultado de una paz así? Otra guerra" ${ }^{15}$.

La mística de Wilson, como todas las visiones místicas, no se encuentra en absoluto exenta de lucidez. La consolidación democrática, en efecto, exige que "los cínicos del mundo" sean apartados de todo protagonismo en la

${ }^{15}$ DÖBLIN, A.: El regreso de las tropas del frente..., pp. 115, 118-119 y 117: “...El mariscal Foch declara que ha vencido con los ejércitos, entre los que también estaban los nuestros... Pero no es más que la mitad del trabajo. Luego vine yo con la segunda arma, la moral. Un gran pueblo no abandona su causa sin más. Las derrotas estimulan y aumentan la energía combativa. Eso cambia cuando las cosas en el interior de los pueblos van mal y la moral no sirve de nada. Ése fue el caso de los alemanes... Pero quiero apuntar en mi haber que los alemanes hayan conseguido tirar por la borda a quienes los dominaban. Ahora, todo depende de guiarlos de forma correcta. Porque podrían convertirse en un bastión de la paz en Europa". 
vida institucional. En ese contexto, y cuando fracasan las primeras conversaciones entre los aliados debido, entre otros motivos, a sus exigencias territoriales y estratégicas a Alemania, especialmente crudas por parte de Georges Clemenceau, Woodrow Wilson no puede evitar referirse a la concepción del Derecho que exhibe el primer mandatario francés, en donde su definición como "organización de fuerzas históricas" que, en ocasiones, "reclaman refuerzo", conduce casi al umbral del decisionismo político, avala la lógica de la victoria que legitima, y no de la victoria legítima, y de la derrota que conduce a un conjunto de sentimientos que, lejos de la acción emancipadora del Derecho, únicamente puede conducir a los vencidos al afán de revancha:

“...Clemenceau definió en una ocasión la paz de una manera que no está mal: una distribución de fuerzas de la que cabe suponer que tiene un equilibrio duradero, y en la que la fuerza moral del Derecho se rodea de garantías estratégicas contra las perturbaciones. No está mal, puedo aceptarlo. Pero si Clemenceau pregunta qué es el Derecho ocurre algo curioso, que muestra lo que pasa con Clemenceau. Dice: el Derecho es una organización de fuerzas históricas que, de vez en cuando, reclaman refuerzo... Eso es Europa: fuerzas históricas que, de vez en cuando, se debilitan y tienen que ser reforzadas. Todo muy bien, muy correcto... sólo que falta el Derecho. Depende, en cada momento, de que el vencedor muestre que conoce el Derecho, un Derecho absoluto, y lo reconozca. Tiene que empezar por la confianza. La victoria le ha impuesto ese deber. De los vencidos sólo puede esperarse la amargura, el odio y el ansia de venganza" ${ }^{16}$.

Woodrow Wilson, no tuvo posibilidad de persuadir a sus aliados, y el 29 de mayo de 1919 abandonó París. Cuando regresó a los Estados Unidos,

\footnotetext{
${ }^{16}$ Ibídem, pp. 590-591 y 588-589: "Si tuviera que reducir Europa a una fórmula sencilla, me refiero a la Europa política, que es la que me ocupa, diría que es una vieja y cínica cultura. Tratan de reanimarse con la guerra. Y en ese escalón se tocan realmente cultura y barbarie. Sólo que hay dos clases de guerra. Una, tosca, nace de la necesidad y la brutalidad. La otra es la guerra perversa que se busca de forma arbitraria e indiferente porque uno ya no se soporta a sí mismo, porque no aguanta dentro de su piel. De ahí que, en algunos de estos pueblos, exista ese culto a la muerte que a nosotros nos es tan incomprensible, y que es muy distinto del simple desprecio a la muerte de los espartanos. Es una cínica indiferencia hacia la vida. Por eso ahora me repele todo su arte, que siempre había admirado. Es cierto que en su arte hay una gran humanidad, armonía y moral. Pero imaginan que con él pueden dispensarse de la humanidad en la vida"
} 
tampoco fue capaz de convencer al Senado para que ratificara el Tratado que establecía la Sociedad de Naciones ${ }^{17}$. En el final de su segundo mandato presidencial, sus expectativas de reelección se esfumaron. Cayó enfermo. Un predicador le visitaba a menudo. También el padre y el abuelo de Wilson los habían sido. Y Alfred Döblin nos muestra al formador e hijo de formadores que, habiendo sido educado en la convicción de que el aprendizaje humano partía "del interior, del centro", se enfrentaba a su dimensión política para captar, en los episodios finales de su existencia, un hecho tan terrible como el haber "trabajado desde fuera". Y eso, para el académico y ciudadano, equivalía a un terrible descubrimiento: "rompemos más de lo que conformamos":

"Mi padre y mi abuelo tenían que llevar la palabra de Dios a los hombres. Ésa era sun índole y su oficio, formar personas. A mí se me ocurrió estudiar, enseñar... y la política. No podía conservar mi conocimiento para mí mismo. Lo admito, siempre es una cierta intolerancia y autoritarismo lo que lleva a la política. Pero, ¿cuál es la verdadera diferencia entre mi forma de ser y la de mi padre y abuelo' Ellos partían del interior, del centro. Tenían un crisol que fundía las viejas verdades sagradas, con el que podían hacer a las personas móviles y fluidas. Nosotros los políticos somos malos en eso. Trabajamos desde fuera. Rompemos más de lo que conformamos...

Como presidente de los Estados Unidos nunca me he dejado arrebatar los derechos que me correspondían dentro de la Constitución. $\mathrm{Y}$ así es como hay que sentarse en la democracia de los pueblos, como vencedor, en el sitio de un liderazgo responsable. Ya no cabe discutir sobre la cooperación común. Ése es el resultado de la guerra. Como se está en posesión del principio correcto y digno, la democracia, se tiene la facultad de ordenar los pueblos en un organismo natural. Ya no se votará por pertenencia a esta o aquella nación. La nación del mañana, la única que hay, es la federación mundial de los pueblos. Hay que terminar con las nacionalidades engendradas y mantenidas de forma artificial. Ya no responden al mundo de hoy. El mundo se ha hecho más grande y más dependiente. La técnica y la economía lo han cambiado todo. La política tiene que seguirlas, cuando no precederlas. Los vencedores democráticos velarán por la educación de las

${ }^{17}$ BENDINER, E.: A Time for Angels. The Tragicomic History of the League of Nations. New York. 1975, pp. 151 y ss. $C f r$. también VISCOUNT CECIL (LORD ROBERT CECIL): $A$ Great Experiment. An Autobiography. London. 1941, pp. 81 y ss. 
viejas naciones de antaño y su adaptación a un nuevo marco natural y moderno. Ah, tendrán que volver a vencer" ${ }^{18}$.

Tras la Gran Guerra y los Tratados de Versalles, los vencedores, en efecto, se obligaron a "volver a vencer" militarmente como garantía de la paz. Que la única victoria eran la paz y la democracia no habría de captarse hasta la finalización de la II Guerra Mundal. El Wilson historiográfico presidente en guerra no había sido en absoluto un inocente defensor del equilibrio democrático entre los pueblos de Europa y, de hecho, su concepción de los Catorce Puntos en modo alguno había previsto que los pueblos germánicos procedieran a decidir libremente su futuro ${ }^{19}$. Pero el Wilson cansado, enfermo y abrumado por su histórica responsabilidad de Alfred Döblin despierta tardía y amargamente a sus errores, unos errores que nacen de la aceptación de la despiadada visión del Derecho o de sus aliados, o más bien de su propia timidez o incapacidad a la hora de sostener la necesidad de un nuevo tiempo para el Derecho y los derechos.

El pueblo traicionado, el tercero de los volúmenes de la tetralogía, viene a aportar un nuevo escenario al análisis de la crisis alemana y, por extensión, europea, de 1918 y 1919: el que aporta el desafío revolucionario berlinés del final del año 1918. Mientras Karl Liebneckt llama desde Berlín a la revolución proletaria, era Kurt Eisner quien, como primer ministro del Estado Libre de Baviera, por él proclamado el 8 de noviembre precedente, tres días antes del final de las hostilidades, había adoptado la iniciativa de dirigir el 12 noviembre de 1918 una declaración a los gobiernos de los aliados y a los proletarios de todo el mundo en donde apelaba a su buena voluntad para construir una nueva civilización, esta vez no inspirada por el capitalismo, sino por el socialismo, dentro de una perspectivamente nuevamente esquemática de la historia:

${ }^{18}$ DÖBLIN, A.: El regreso de las tropas del frente..., pp. 629 y 632-633: “....Los pueblos aún no han sufrido lo bastante como para querer la verdadera paz... Lo que los políticos hacemos ha de hacerse, en el seno del Estado, en el Gobierno, y en indeciblemente trabajoso. Trabajamos en medio del frío, la suciedad y la humedad, y todo se nos escapa entre los dedos. Tenemos que levantar un dique contra le ferocidad humana, los necios egoísmos y la maldad".

${ }^{19}$ MÖLLER, H.: Die Weimarer Republik. Eine unvollendete Demokratie. München. 2008, pp. 140 y ss. 
"El pueblo bávaro, dirigido por hombres que desde el comienzo de la guerra han librado una lucha apasionada contra la criminal política de los gobiernos y príncipes alemanes, ha sido el primero de Alemania en suprimir, en un impetuoso levantamiento revolucionario coronado por el éxito definitivo, todo aquello que tuvo culpa y complicidad en la Guerra Mundial. Baviera se ha proclamado Estado Libre, el pueblo entero celebra su liberación. En este momento, la publicación de las condiciones de armisticio de las potencias aliadas cae sobre la joven Baviera. La nueva república será en breve presa de la desolación y el caos. Ahora ha llegado la hora en que, con un acto de generosidad y visión de futuro, puede producirse la reconciliación de los pueblos. La Sociedad de Naciones nunca podrá existir si empieza por erradicar el eslabón más joven de la cultura democrática. El destino de la Humanidad está en manos de los hombres que ahora son responsables de traer la paz y de dar nueva forma a unos pueblos arruinados" ${ }^{20}$.

La construcción de la naciente nueva institucionalidad democrática alemana, en efecto, obedecía a una lógica reformista y burguesa ${ }^{21}$. Pero el final de la contienda no únicamente había dejado a una amplia clase media en el umbral de la proletarización. Alfred Döblin hace notar que se había instalado entre los suboficiales, quienes no formaban parte de los soldados, pero tampoco de la oficialidad, lejos del pueblo bajo, pero también de las clases dirigentes, un profundo malestar que prontamente había derivado hacia un profundo resentimiento social. Alfred Döblin hace notar que no eran precisa-

${ }^{20}$ DÖBLIN, A.: Noviembre de 1918. El pueblo traicionado. Barcelona. 2017, pp. 193-194 y 252: "El proletariado alemán no quiere la paz de Wilson, sino una socialista. Porque quiere la abolición del capitalismo. Sólo con la socialización puede construirse una nueva economía de paz... Pero erradicar el capitalismo, implantar el orden social socialista, sólo es posible a escala internacional. Se duda de si vendrá la revolución en Francia, Inglaterra, Italia, América... porque hasta hoy no ha venido...

...la revolución alemana aún no es socialista, y no podemos esperar engendrar con este cambio otra revolución en las democracias occidentales que hace mucho que ya tienen una república burguesa como ésta... no desencadenaremos revolución alguna en ellas, y no alcanzaremos una paz verdadera si en nuestro país no avanzamos de la reforma burguesa de Ebert y Scheidemann a la revolución social...

Hay dos posibilidades para liquidar la guerra: la capitalista-imperialista y la proletariosocialista. La primera arroja una paz momentánea y sin dignidad humana. La segunda es la paz del bienestar duradero. La primera conserva las clases, la segunda libera al pueblo".

${ }^{21}$ REINHARD, W.: Geschichte der Staatsgewalt. Eine vergleichende Verfassungsgeschichte Europas von den Anfängen bis zue Gegenwart. München. 2000, pp. 422-423. 
mente unos sentimentales, "pero tenían mujer e hijos, y no un empleo fijo, y con eso no se podía bromear". A partir de esta circunstancia, el estado de ánimo devino en estado de cosas: un conjunto de profesionales de la guerra bien entrenados, mejor organizados, llenos de orgullo, no conscientes de haber sido derrotados en el campo de batalla, y dotados de una enorme experiencia, se encontraron de regreso en Alemania desocupados y desprestigiados, pero en modo alguno se sintieron ajenos a la nueva realidad política de su país ${ }^{22}$. Mientras, los peores presagios acerca del porvenir de Alemania y de Europa eran explícitamente formulados por las cabezas más lúcidas ${ }^{23}$. Pero en modo alguno podían llegar a imaginar hasta qué punto la realidad iba a desbordar sus predicciones.

Karl y Rosa, es decir, Karl Liebknecht y Rosa Luxemburgo, el volumen que cierra la tetralogía, viene a plantear, en conclusión, el problema de fondo que en todo momento late en Noviembre de $1918 \mathrm{y}$, de modo permanente a lo largo de toda la producción novelística de Alfred Döblin, pero especialmente en su etapa final: ese problema es la relación del ser humano concreto con el poder, es decir, con un poder tan despiadado como siempre, pero ahora dotado de nuevas herramientas técnicas. La relación, en la antigua y en la nueva Alemania, del ser humano con el Estado. Y uno de los anónimos protagonistas del corpus narrativo de Alfred Döblin, Becker, formula ese problema en términos cuya vigencia no puede resonar con mayor rotundidad, tanto en 1919 como en 2019:

“¿Cómo hay que conducirse frente al Estado?, pregunta Sófocles. No se pone las cosas fáciles... No discute que los pequeños sentimientos personales tienen que retroceder ante las necesidades generales. Antígona, fijense

${ }^{22}$ DÖBLIN, A.: El pueblo traicionado..., pp. 520-521: “Celebraban sus reuniones, bebían, fumaban y hablaban. Y entre los suboficiales había subtenientes, brigadas, sargentos, sargentos mayores, oficiales de pagaduría, habitantes apátridas de los cuarteles, y gemían por el destino de Alemania... fundaron una asociación, la alianza de suboficiales en activo... había que comparecer y hacer una declaración de lealtad a ese Gobierno. Las declaraciones de lealtad son propias de las asociaciones...

...Qué acción, esa declaración, no sólo para ellos mismos, sino para el Estado, para Alemania, incluso para el mundo. Unos suboficiales vigorosos, semilla del pueblo sano, al lado del Gobierno, ¡qué más se podía decir!”.

${ }^{23}$ KEYNES, J. M.: Las consecuencias económicas de la paz. Barcelona. 1987, pp. 189-190. 
bien en esto, no se enfrenta al poder del Estado, encarnado en el rey, como un particular cualquiera, sino que defiende un principio al menos tan legítimo como el que representa el rey. Usted decía, Schramm, que era una rebelde que llamaba a la revolución. Es valiente, pero no es una rebelde. Es lo contrario de una revolucionaria. Si hay alguien revolucionario en la obra es -...- Creonte, el rey... Sí, él, en lo que de hecho es su voluntad tiránica, en su orgullo de ser vencedor y al fin rey, cree poder situarse por encima de tradiciones sagradas, de evidencias antiquísimas. Porque en la cultivada Grecia era una obviedad que la familia llora y entierra a sus muertos. Ella tenía la obligación de practicar en el entierro ciertas ceremonias y honrar a los dioses de los muertos. Creonte cree que puede ignorar todas esas piadosas costumbres. Cree que, después de haber vencido y aniquilado al enemigo, puede hacer lo que quiera con él, incluso más allá de la muerte. Pero hay fronteras que han sido fijadas por otro poder. Choca con lo sobrenatural. De ahí se desprenden leyes que nadie puede remover, y que son tan fuertes que pueden permitirse hablar por boca de una débil muchacha. Porque esos poderes invisibles han depositado sus leyes en el más seguro de los lugares, en los corazones de los humanos. A esa Ley no escrita se acoge Antígona...." 24.

Becker ha acudido a Sófocles y su Antígona, es decir, una de esas obras que Italo Calvino definía en ¿Por qué leer los clásicos? como una creación que generación tras generación ofrece nuevas lecturas y lecciones a partir de un supuesto intemporal, una de esas obras que nos llena cuando la realidad se vacía, para inmediatamente transitar desde la Antigüedad al año 1914, y de los humanos que son juguetes de los dioses a los humanos que se han convertido en juguetes de un "Dios viviente" denominado Estado ${ }^{25}$ :

-"Tomemos un ejemplo práctico. Ninguno de los que fuimos a la guerra en 1914 nos hicimos la pregunta de si aquello era por derecho divino o ra-

${ }^{24}$ DÖBLIN, A.: Noviembre de 1918. Karl y Rosa. Barcelona. 2014, pp. 249-250: "Una vez más, tomó la palabra el fino y pulido Schröter, el delegado, para observar, con su voz uniforme, tranquila y fría:

-Sin querer atentar contra la vigencia de esa doctrina de la Ley no escrita, quisiera plantear una pregunta: ¿hasta dónde se llega con eso? El Estado tiene que confiar en algo. Tiene que trabajar con parágrafos claros, fijados de una vez para siempre. En los parágrafos de un código escrito se expresa la moral de un pueblo. No se puede, bajo ninguna circunstancia, dar a los ciudadanos la posibilidad, y menos aún en tiempos de guerra, de invocar inspiraciones divinas con las que pueden llevar al caos toda la vida del Estado".

${ }^{25}$ CALVINO, I.: ¿Por qué leer los clásicos? Barcelona. 1993, pp. 14 y ss. 
zón de Estado. Fue como en 1813, el rey llamó, y todos, todos acudimos. Éramos hombres, habíamos prestado juramento de lealtad y seguimos a la bandera. Ninguno de los que conocí, ninguno, criticó ni una vez al Estado, nuestro Estado, ni se apartó de él como individuo. Ninguno de nosotros dudó en ir a la muerte por él...

-Obedecimos. La antítesis: en tiempo de paz, el individuo existe constantemente frente al Estado. Debe y tiene que existir, porque somos quienes sustentamos el Estado...

-Es algo terrible caer en manos de un Dios viviente. Eso también lo demostró esta guerra. En Alemania estábamos felices. Y así fue como fuimos a la guerra. Nos empleamos con todas nuestras fuerzas, con toda nuestra voluntad y conocimientos..., y nos desplomamos, como colectivo. En estas circunstancias, es absurdo e indigno buscar criminales de guerra, como ahora se hace dentro y fuera del país. Leemos que nuestros antiguos adversarios preparan listas de nombres, de hombres que se supone serían los auténticos culpables de la guerra. Todos, jóvenes y viejos, los que vivimos, los que vimos antes de la guerra y participamos en ella, aquí y allí, somos culpables. Todo el mundo, el pueblo, fue a la guerra, y fue castigado" 26.

Döblin sostiene que la conversión del Estado en esa deidad abrumadora fue aceptada por la ciudadanía alemana de manera acrítica en 1914. Ni que decir tiene que, partiendo de esos presupuestos, resulta sumamente más entendible cuanto habría de suceder en 1933. Cuando se asume que el Derecho es "una organización de fuerzas históricas", y existe un agente que antes y, sobre todo, durante y tras la toma del Estado, determina en qué consiste lo histórico, y detenta toda la fuerza, la consecuencia es la tiranía sobre los vivos, pero también sobre unos muertos que, como en la Antígona de Sofócles, no conservan ni su sagrado derecho al entierro. O, como mantiene Alfred Döblin, la interrogante en torno a la relación entre ciudadano y Estado se convierte en la pregunta por la Muerte ${ }^{27}$.

\footnotetext{
${ }^{26}$ DÖBLIN, A.: Karl y Rosa..., pp. 276-277.

${ }^{27}$ DÖBLIN, A.: Karl y Rosa..., pp. 278-279: “-Detrás de la pregunta 'Estado e individuo' o 'Deber para con el Estado y ley no escrita' se esconde la pregunta por la Muerte...

...La obra trata del derecho legal de un muerto sobre los vivos. Un guerrero ha caído. No ha dejado atrás una memoria limpia. Ese muerto no es visible ni perceptible, ni siquiera audible, pero se abre paso hasta la esfera de los vivos y encuentra un abogado en su hermana Antígona. Es una mujer la que se hace cargo de él... Porque lo que él reclama es su derecho.
} 
La imagen es poderosísima. El nuevo orden democrático y republicano, pero sobre todo el futuro orden totalitario y estatólatra no se construye únicamente sobre los vivos, sino también, y de manera fundamental, sobre los muertos. Los que cayeron en los campos de batalla, los que perdieron la vida en la retaguardia, y los que perecieron trágicamente en las revoluciones.

Alfred Döblin tuvo el acierto, la sensibilidad y la lucidez de detectar, constatar y explicar, en forma narrativa, las raíces profundas de la agresión totalitaria. De comprobar hasta qué punto el nuevo Estado que nacía de la Gran Guerra, y del Diktat de los vencedores en Versalles, no tardaría en verse usurpado por quienes, valiéndose de su pulcritud democrática, habrían de convertirlo en un instrumento para la dominación de los vivos apoderándose de una Historia convertida en manipulación de la memoria de los muertos. No debe resultar extraño que un riguroso contemporáneo de Alfred Döblin, como fue el escritor inglés Christopher Isherwood, residente en el Berlín de los años que van de 1930 a 1932, considerara la irrupción del nazismo en la mismísima cancillería como un hecho inevitable, casi inspirado por la invencible fatalidad ${ }^{28}$.

Pero fue en Noviembre de 1918, como el escritor de Stettin habría de demostrar, cuando los heraldos del totalitarismo se establecieron en Alemania. Casi exactamente un siglo después, y transcurridas casi siete décadas desde la publicación de la obra, las reflexiones de Alfred Döblin conservan una extraordinaria vigencia. Por muchos conceptos, una escalofriante vigencia.

Ella habla por él y expone sus argumentos. El muerto reclama un pilar de su existencia... la vida de los muertos no coincide con su existencia visible...".

${ }^{28}$ ISHERWOOD, C.: Adiós a Berlín. Barcelona. 1995, pp. 233 y ss. 